\title{
Thymidine Phosphorylase/ $\beta$-tubulin III expressions predict the response in Chinese advanced gastric cancer patients receiving first-line capecitabine plus paclitaxel
}

\author{
Jing $\mathrm{GaO}^{\dagger}$, Ming Lư ${ }^{\dagger}$, Jing-wei Yu, Yan-yan Li and Lin Shen*
}

\begin{abstract}
Background: To assess the role of Thymidine Phosphorylase and $\beta$-tubulin III in clinical outcome of Chinese advanced gastric cancer patients receiving first-line capecitabine plus paclitaxel.

Methods: The clinical data and tumor biopsies prior treatment from 33 advanced gastric cancer patients receiving capecitabine plus paclitaxel (cohort 1, experimental group) and 18 patients receiving capecitabine plus cisplatin (cohort 2, control group) in Beijing Cancer Hospital from July 2003 to December 2008 were retrospectively collected and analyzed for Thymidine Phosphorylase and $\beta$-tubulin III expressions by immunohistochemistry. The relationships between expressions of biomarkers and response or survival were determined by statistical analysis.

Results: The median age of 51 patients was 57 years (range, 27-75) with male 34 and female 17, and the response rate, median progression-free survival and overall survival were $43.1 \%, 120 \mathrm{~d}$ and $265 \mathrm{~d}$. Among cohort 1 , the response rate, median progression-free survival and overall survival in $\beta$-tubulin III positive $(n=22)$ and negative patients $(n=11)$ were $36.4 \% / 72.7 \%$ (positive vs negative, $P=0.049), 86 \mathrm{~d} / 237 \mathrm{~d}(P=0.046)$ and $201 \mathrm{~d} / 388 \mathrm{~d}(P=$ 0.029), respectively; the response rate $(87.5 \%$ vs $14.3 \%, P=0.01$ ) and median progression-free survival (251d vs $84 d$, $P=0.003)$ in Thymidine Phosphorylase positive \& $\beta$-tubulin III negative patients $(n=8)$ were also significantly higher than those in Thymidine Phosphorylase negative $\& \beta$-tubulin III positive patients $(n=7)$. There was no correlation between $\beta$-tubulin III expression and response or survival among cohort $2(n=18)$.

Conclusions: In Chinese advanced gastric cancer, Thymidine Phosphorylase positive \& $\beta$-tubulin III negative might predict response and prognosis to capecitabine plus paclitaxel chemotherapy. Further prospective evaluation in large samples should be performed to confirm these preliminary findings.
\end{abstract}

\section{Background}

Gastric cancer remains one of the most common causes of cancer death worldwide [1], especially in China [2]. Although the improvement of diagnostic methods enables some patients to receive radical cure at early disease, about $40 \%$ patients still miss the opportunity of radical cure at the time of diagnosis, furthermore, about $50 \%$ patients occur relapse and metastasis after operation. For these patients, chemotherapy is still the main

\footnotetext{
* Correspondence: lin100@medmail.com.cn

† Contributed equally

Key laboratory of Carcinogenesis and Translational Research (Ministry of Education), Department of Gl Oncology, Peking University School of Oncology, Beijing Cancer Hospital \& Institute, Beijing, China
}

method general accepted in the world. Several agents are now available for the systemic chemotherapy of patients with gastric cancer, including fluoropyrimidines, platinum, taxanes and so on. But fluoropyrimidines are fundamental in gastric cancer. For advanced gastric cancer patients (AGC), combination chemotherapy with two or three drugs is most common with superiority compared to best supportive care in first-line or secondline therapy [3-6].

Capecitabine is an orally-administered chemotherapeutic agent which was designed to generate 5-Fluorouracil (5-FU) preferentially in tumors. It is a prodrug which is converted to 5 -FU in the tumors through a
C Biomed Central 
pathway with three enzymatic steps and two intermediary metabolites involved in. At the last enzymatic step, the metabolite 5'-deoxy-5-fluorouridine (5'-DFUR) is converted to 5 -FU by Thymidine Phosphorylase (TP) which is more active in tumor tissues than in normal tissues [7]. So, the overexpression of TP in tumor tissues can increase the concentration of 5-FU and thus enhance the anticancer effect. Current evidences indicate that the expression level of TP may influence the clinical outcome of capecitabine in non-small cell lung cancer, gastrointestinal adenocarcinoma, breast cancer, head and neck cancer, and so on [8-11]. Two large phase III clinical trials showed that capecitabine could substitute 5-FU in clinical administration [12,13]. Also capecitabine combined with cisplatin or paclitaxel has been proved to be an effective combination regimen used in patients with advanced gastric cancer as firstline or second-line treatment [13-15].

Taxane including paclitaxel (PTX) and docetaxel, is another active antitumor agent for gastric cancer. Taxane binds to $\beta$-tubulin, which is one of the major components of microtubule, and exerts its growth-inhibitory effects through the stabilization of microtubule, resulting in the growth arrest of tumor cells at the G2/M phase [16]. Several mechanisms have been suggested as responsible for taxane resistance: (1) The overexpression of MDR1 gene which encodes P-glycoprotein able to efflux taxanes and other cationic drugs, thereby hampering drug retention [17]; (2) Point mutation in tubulin has been identified to be responsible for taxane resistance $[18,19]$. (3) The selective overexpression of $\beta$-tubulin isotypes is another mechanism of resistance [20]. Up to now, at least seven distinct $\beta$-tubulin isotypes (classes I, II, III, IVa, IVb, V and VI) have been reported in human, with a complex distribution pattern in various tissues [20]. Some researches found the presence of class III $\beta$-tubulin ( $\beta$-tubulin III, TUBB3) inhibited the assembly of $\beta$-tubulin subunits promoted by paclitaxel [21] and TUBB3 expressed in some paclitaxel-resistant cells [22]. Many preclinical studies have shown high expression levels of TUBB3 are associated with paclitaxel resistance in human lung cancer [23], ovarian cancer [22], prostate cancer [24] and breast cancer [25] cell lines. In studies of lung cancer, breast cancer and ovarian cancer, there are reverse relations between TUBB3 expression and paclitaxel efficacy or prognosis of patients [26-28].

Now that the target of paclitaxel is $\beta$-tubulin, and study had reported that there were rare mutations in $\beta$ tubulin for gastric cancer (no mutations were found in 50 tumor samples) [29], we considered that the overexpression of TUBB3 was the most probable mechanism of paclitaxel resistance in gastric cancer. This study was designed to demonstrate the clinical implications of TP and TUBB3 expressions in capecitabine plus paclitaxel chemotherapy for advanced gastric cancer patients, and to identify potential predictors for patients with gastric cancer treated with capecitabine plus paclitaxel.

\section{Methods}

\section{Patients Eligibility}

All patients in this study were retrospectively collected as following criteria: patients had histologically confirmed metastatic gastric adenocarcinoma and at least one measurable lesion according to the response evaluation criteria in solid tumors guidelines [30]; patients were treated by capecitabine plus paclitaxel or cisplatin in gastrointestinal department of Beijing Cancer Hospital from July 2003 to December 2008, and had completed at least two cycles of chemotherapy; no any chemotherapy except for neoadjuvant or adjuvant chemotherapy (adjuvant chemotherapy completed over 12 months) was done; all patients underwent endoscopic biopsy from primary stomach before chemotherapy.

\section{Treatment Regimens}

The first-line chemotherapy regimens with capecitabine plus paclitaxel or cisplatin were administered to patients as following: capecitabine (Roche Laboratories Inc., Nutley, NJ) was given orally at a dose of $1,250 \mathrm{mg} / \mathrm{m}^{2}$ twice daily from day1 (d1) to day14 (d14) of 3-weeks cycle; paclitaxel (Hainanhaiyao Co., Ltd., China) was given at a dose of $80 \mathrm{mg} / \mathrm{m}^{2}$ by a 180 -min i.v. infusion on $\mathrm{d} 1$ and d8 of each cycle; cisplatin (Qilu Pharmaceutical CO., LTD., China) was given at a dose of $80 \mathrm{mg} / \mathrm{m}^{2}$ by a 240-min i.v. infusion on d1 of each cycle. Treatment was continued until disease progression or unacceptable toxicity, or patients/physicians' decision.

\section{Response Evaluation}

Chemotherapeutic response was evaluated every two months by computed tomography (CT) according to the Response Evaluation Criteria in Solid Tumors (RECIST) criteria. Patients were categorized by complete response (CR), partial response (PR), stable disease (SD), and progressive disease (PD). $C R$ and $P R$ patients were defined as responders, SD and PD patients as nonresponders. The progression-free survival (PFS) and overall survival (OS) were calculated from the first day of therapy to disease progression and death from any cause, respectively.

\section{Immunohistochemistry analysis for TP and TUBB3}

All tumor samples were retrospectively collected from patients, and two step method of immunohistochemistry (IHC) was used to detect TP and TUBB3 in tumor sections. Formalin-Fixed Paraffin-Embedded tissue sections with $4 \mu \mathrm{m}$ thick were deparaffinized in xylene 
and hydrated in graded alcohols. After antigen retrieval in $0.01 \mathrm{M}$ citrate buffer ( $\mathrm{pH} 6.0$ ), sections were treated with endogenous peroxidase confining liquid (Beijing CoWin Biotech Co., Ltd., Lot. CW0117) for $10 \mathrm{~min}$. Sections were rinsed and incubated with TUBB3 and TP (Beijing CoWin Biotech Co., Ltd.) monoclonal antibodies for $60 \mathrm{~min}$, respectively. After rinsing in phosphate buffered saline (PBS), the sections were incubated with general type IgG-HRP Polymer (Beijing CoWin Biotech Co., Ltd., Lot. CW0117) for $10 \mathrm{~min}$, followed by chromogenic 3,3'-Diaminobenzidine tetrahydrochloride dihydrate (DAB) for about 2-7 min. Finally, sections were conterstained with hematoxylin for $1 \mathrm{~min}$ followed by dehydrated in graded alcohols, cleared in xylene, and covered with coverslips. Each experiment included negative control. Sections were examined and scored by two independent professional pathologists of pathology department without any knowledge of this study. TP protein was distributed in cytoplasm and nuclear, TUBB3 in cytoplasm. Staining was graded for intensity of staining according to previous description [31]. Briefly, intensity of staining (1, weak; 2, moderate; 3 , strong) and percentage of cells stained (1, 0\% 10\%; 2, 11\% 50\%; 3, 51\% 100\%) were calculated. At last, the expression levels were considered to be positive or negative based on the median staining score (intensity score plus percentage score) as following: negative for score $\leq 3$, positive for score $>3$.

\section{Statistical Analysis}

According to TP and TUBB3 protein expression levels, patients were divided into two groups (positive and negative). The relationships between TP, TUBB3 expressions and response to capecitabine plus paclitaxel or cisplatin were analyzed using Fisher's exact test. KaplanMeier curves and log-rank test were used to analyze the association between expression levels of biomarkers and survival. Statistical analysis was done using SPSS 13.0 (SPSS Inc, Chicago, Illinois, USA).

\section{Results}

\section{Patient Demographics}

Fifty-one patients were included in this study between July 2003 to December 2008 in our hospital with male 34 , female 17, median age 57 years (range 27-75 years). Thirty-three patients (male 20, female 13, median age 57 years [range 27-74 years]) received capecitabine plus paclitaxel with a median 6 cycles of chemotherapy (cohort 1) and eighteen patients (male 14, female 4, median age 57 years [range $42-75$ years]) received capecitabine plus cisplatin with a median 6 cycles of chemotherapy (cohort 2). The characteristics of 51 patients are presented in Table 1.

\section{Response Evaluation and Survival}

Up to February 2010, all patients had been evaluable for response and 43 patients died. The overall response rate $(C R+P R)$ in 51 patients was $43.1 \%$, with 22 partial

Table 1 Patient Demographics and Clinical Characteristics

\begin{tabular}{|c|c|c|c|c|c|c|}
\hline \multirow[t]{2}{*}{ Characteristic } & \multicolumn{2}{|c|}{ Cohort $1(n=33)$} & \multicolumn{2}{|c|}{ Cohort $2(n=18)$} & \multicolumn{2}{|c|}{ Total $(n=51)$} \\
\hline & No. of Patients & $\%$ & No. of Patients & $\%$ & No. of Patients & $\%$ \\
\hline \multicolumn{7}{|l|}{ Sex } \\
\hline Male & 20 & 60.6 & 14 & 77.8 & 34 & 66.7 \\
\hline female & 13 & 39.4 & 4 & 22.2 & 17 & 33.3 \\
\hline \multicolumn{7}{|l|}{ Age, years } \\
\hline Median & \multicolumn{2}{|l|}{57} & \multicolumn{2}{|l|}{57} & \multicolumn{2}{|l|}{57} \\
\hline Range & \multicolumn{2}{|l|}{$27-74$} & \multicolumn{2}{|l|}{$42-75$} & \multicolumn{2}{|l|}{$27-75$} \\
\hline \multicolumn{7}{|l|}{ KPS } \\
\hline $90-100$ & 23 & 69.7 & 14 & 77.8 & 37 & 72.5 \\
\hline $70-80$ & 10 & 30.3 & 4 & 22.2 & 14 & 27.5 \\
\hline \multicolumn{7}{|l|}{ Sites of metastatic disease } \\
\hline Liver & 12 & 36.4 & 6 & 33.3 & 18 & 35.3 \\
\hline Lung & 1 & 3.0 & 4 & 22.2 & 5 & 9.8 \\
\hline Lymph nodes & 33 & 100 & 17 & 94.4 & 50 & 98.0 \\
\hline Peritoneum & 6 & 18.2 & 3 & 16.7 & 9 & 17.6 \\
\hline Others* & 8 & 24.2 & 4 & 22.2 & 12 & 23.5 \\
\hline \multicolumn{7}{|l|}{ Histological differentiation ${ }^{\#}$} \\
\hline Poor & 25 & 75.8 & 11 & 61.1 & 36 & 70.6 \\
\hline Good & 8 & 24.2 & 7 & 38.9 & 15 & 29.4 \\
\hline
\end{tabular}

NOTE: *Including ovary, adrenal glands, subcutaneous of abdominal wall, pelvic cavity, bone and thoracic cavity. "Poor, including poorly differentiated adenocarcinoma, signet ring cell carcinoma and mucinous adenocarcinoma; Good, including moderate-well differentiated adenocarcinoma. KPS, Kamofsky performance status. 
responders $(43.1 \%), 18$ patients with stable disease (35.3\%), and 11 patients with progressive disease (21.6\%). The median PFS and OS of 51 patients were 120 days and 265 days, respectively. There were no significant differences of response and survival between cohort 1 and cohort 2 (Table 2). The response rate, median PFS and OS in cohort 1 and cohort 2 were 48.5\%, 120 days, 252 days and 33.3\%, 116 days, 265 days, respectively.

\section{TP IHC and Response, Survival}

Negative and positive staining for TP protein in 51 tumor samples were 26 and 25 samples (Figure 1, left lane). Of the 25 patients with positive TP, there were 14 responses $(56 \%)$, compared with 8 of 26 responses (30.8\%) seen in negative TP tumors $(P=0.069$, Table $3)$. Also, the median PFS and OS in TP positive samples were longer than that in TP negative samples, but significant difference only existed in OS $(P=0.017)$ not in PFS $(P=0.613)$ between two groups (Table 3$)$.

\section{TUBB3 IHC and Response, survival}

IHC of TUBB3 was done in cohort 1 and cohort 2, negative and positive staining for TUBB3 in cohort 1 (33 samples) were 11 and 22 samples (Figure 1, right lane). Among cohort 1 , of the 22 patients with positive TUBB3, there were 8 responses (36.4\%), compared with 8 of 11 responses $(72.7 \%)$ seen in negative TUBB3 tumors $(P=0.049)$; also, the median PFS $(P=0.046)$ and OS $(P=0.029)$ in TUBB3 positive samples were much shorter than those in TUBB3 negative samples (Table 4 and Figure 2). Among cohort 2, the response rates in TUBB3 negative patients $(\mathrm{n}=7)$ and positive patients $(\mathrm{n}=11)$ were $28.6 \%$ and $36.4 \%$, respectively $(P$ $=0.73)$. Also, there weren't correlations between TUBB3 expressions and median PFS $(P=0.562)$ or OS $(P=$ 0.633 ) in cohort 2 (Figure 3).

Table 2 Response and Survival for all patients

\begin{tabular}{|c|c|c|c|c|c|c|c|}
\hline \multirow[b]{2}{*}{ Outcome } & \multicolumn{2}{|c|}{$\begin{array}{c}\text { Cohort } 1 \text { ( } n= \\
33)\end{array}$} & \multicolumn{2}{|c|}{$\begin{array}{c}\text { Cohort } 2(n= \\
18)\end{array}$} & \multirow[t]{2}{*}{$P$} & \multicolumn{2}{|c|}{$\begin{array}{c}\text { Total }(\mathrm{n}= \\
51)\end{array}$} \\
\hline & No. & $\%$ & No. & $\%$ & & No. & $\%$ \\
\hline CR+PR No. & 16 & 48.5 & 6 & 33.3 & & 22 & 43.1 \\
\hline SD No. & 11 & 33.3 & 7 & 38.9 & & 18 & 35.3 \\
\hline PD No. & 6 & 18.2 & 5 & 27.8 & & 11 & 21.6 \\
\hline Response rate & 16 & 48.5 & 6 & 33.3 & 0.668 & 22 & 43.1 \\
\hline Median PFS (days) & \multicolumn{2}{|c|}{120} & \multicolumn{2}{|c|}{116} & & \multicolumn{2}{|c|}{120} \\
\hline $95 \% \mathrm{Cl}$ & \multicolumn{2}{|c|}{$77.2-162.8$} & \multicolumn{2}{|c|}{$0-267.1$} & 0.377 & \multicolumn{2}{|c|}{$79.7-160.3$} \\
\hline Median OS (days) & \multicolumn{2}{|c|}{252} & \multicolumn{2}{|c|}{265} & & \multicolumn{2}{|c|}{265} \\
\hline $95 \% \mathrm{Cl}$ & \multicolumn{2}{|c|}{ 157. 5-346.5 } & \multicolumn{2}{|c|}{$107.0-423.0$} & 0.354 & \multicolumn{2}{|c|}{$181.0-349.0$} \\
\hline
\end{tabular}

NOTE: PFS, progression-free survival; OS, overall survival; $95 \%$ Cl: $95 \%$ confidence interval

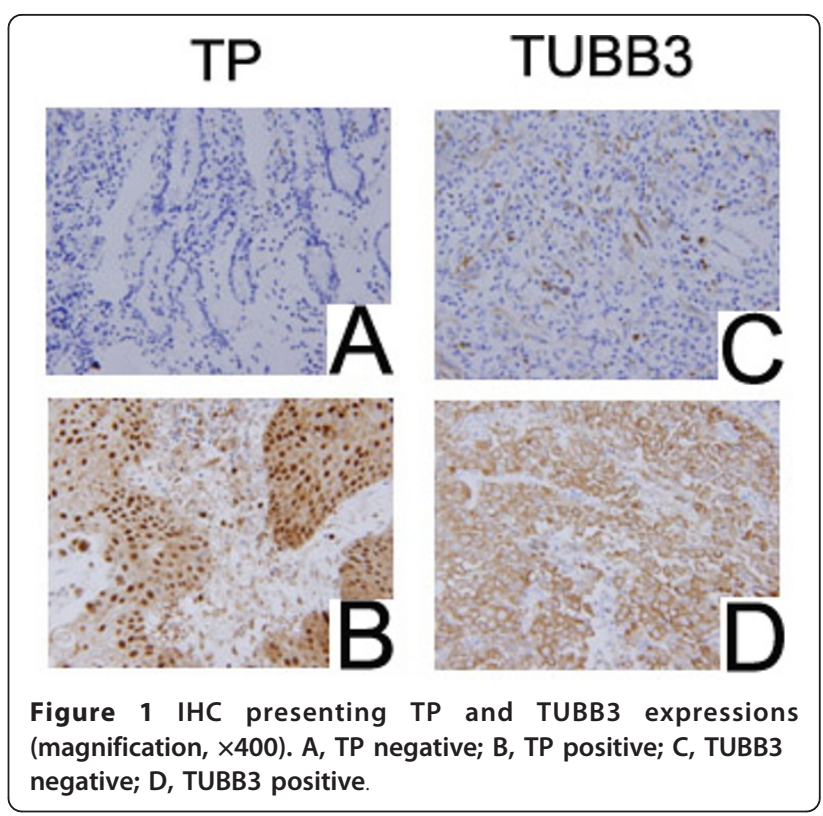

TP, TUBB3 IHC and Response, survival

Among cohort 1 , TP positive \& TUBB3 negative staining was 8 samples, with 7 responses $(87.5 \%)$, but for TP negative \& TUBB3 positive staining samples, only 1 of 7 responses $(14.3 \%)(P=0.01$, Table 5). The median PFS (251d) and OS (393d) in TP positive \& TUBB3 negative staining samples were longer than those (PFS: 84d, OS: 196d) in TP negative \& TUBB3 positive staining samples, although there was no statistical difference of OS between two groups $(P=0.003$ for PFS, $P=0.439$ for OS, Table 5 and Figure 4). There were 15 samples ( 8 responses, $53.3 \%$ ) displaying TP positive \& TUBB3 positive staining with median PFS $122 \mathrm{~d}$ and median OS 207d, and 3 samples (all with SD) displaying TP negative \& TUBB3 negative staining.

Table 3 Association Between TP Expression and Response or Survival

\begin{tabular}{|c|c|c|}
\hline & \multicolumn{2}{|c|}{ TP Staining $(n=51)$} \\
\hline & Positive & Negative \\
\hline CR+PR No. & 14 & 8 \\
\hline SD No. & 5 & 13 \\
\hline PD No. & 6 & 5 \\
\hline Response rate (\%) & 56 & 30.8 \\
\hline$P$ & \multicolumn{2}{|c|}{0.069} \\
\hline $\begin{array}{l}\text { Median PFS (days) } \\
(95 \% \mathrm{Cl})\end{array}$ & $\begin{array}{c}156 \\
(71.5-240.5)\end{array}$ & $\begin{array}{c}107 \\
(66.7-147.3)\end{array}$ \\
\hline$P$ & \multicolumn{2}{|c|}{0.613} \\
\hline $\begin{array}{l}\text { Median OS (days) } \\
(95 \% \mathrm{Cl})\end{array}$ & $\begin{array}{c}365 \\
(123.0-567.0)\end{array}$ & $\begin{array}{c}214 \\
(74.8-317.2)\end{array}$ \\
\hline$P$ & \multicolumn{2}{|c|}{0.017} \\
\hline
\end{tabular}


Table 4 Association Between TUBB3 Expression and Response or Survival

\begin{tabular}{|c|c|c|}
\hline & \multicolumn{2}{|c|}{ TUBB3 Staining } \\
\hline & Positive & Negative \\
\hline CR+PR No. & 8 & 8 \\
\hline SD No. & 9 & 2 \\
\hline PD No. & 5 & 1 \\
\hline Response rate (\%) & 36.4 & 72.7 \\
\hline$P$ & \multicolumn{2}{|c|}{0.049} \\
\hline $\begin{array}{l}\text { Median PFS (days) } \\
(95 \% \mathrm{CI})\end{array}$ & $\begin{array}{c}86 \\
(40.9-131.1)\end{array}$ & $\begin{array}{c}237 \\
(19.4-454.6)\end{array}$ \\
\hline$P$ & \multicolumn{2}{|c|}{0.046} \\
\hline $\begin{array}{l}\text { Median OS (days) } \\
(95 \% \mathrm{Cl})\end{array}$ & $\begin{array}{c}201 \\
(182.5-253.5)\end{array}$ & $\begin{array}{c}388 \\
(67.6-708.4)\end{array}$ \\
\hline$P$ & \multicolumn{2}{|c|}{0.029} \\
\hline
\end{tabular}

\section{Discussion}

The treatment of gastric cancer is still a troublesome problem worldwide, and up to now there is not systematic standard regimen for gastric cancer. Over 50\% patients couldn't respond to chemotherapy with the major obstacle is drug resistance. So how to improve the response and extend the life of patients is requested urgently. At present, the regimen of platinum (cisplatin, oxaliplatin, etc.) combined with fluorouracil (5-FU, capecitabine, etc.) is most used for gastric cancer in China. Capecitabine is a new type flurouracil carbamates antitumor agent and widespread used by tumor patients due to its convenient administration, well tolerance, definite effect and low side effect. Animal experiments have shown that many drugs, such as irinotecan, oxaliplatin, cisplatin and paclitaxel, had synergistic effect with capecitabine [32-34], and capecitabine plus paclitaxel or cisplatin regimens have been considered as desirable chemotherapy in clinical studies [13-15].

Based on our results, the response rate of capecitabine plus paclitaxel or cisplatin was $48.5 \%$ and $33.3 \%$, respectively. However, although these regimens were effective in gastric cancer, over an half patients failed to respond due to drug resistance. So if we can find some predictive biomarkers for capecitabine plus paclitaxel to guide treatment of patients, there must be a very great improvement for response and survival. TP is a key enzyme in the metabolic pathway of capecitabine. TP enzyme, also called tumor related angiogenesis factor, is higher expressed in tumor tissues than in normal tissues, then the concentration of 5-FU in tumor tissues is raised followed by enhanced antitumor activity. In our results, the response rate, PFS and OS for TP positive patients are all higher than that in TP negative patients, which is similar with the results by other researchers [8-11]. According to above results, we analyzed TP expression in advanced gastric cancer and found the overall survival of TP positive patients was much better than that in TP negative patients. However, in different studies of colorectal cancer, data about the prognostic or predictive value of TP were conflicting: Meropol NJ et al [35] reported TP expression might be a predictive marker for capecitabine response, but Koopman et al [36] found TP expression didn't show a predictive or prognostic value for capecitabine combination chemotherapy.

\section{capecitabine plus paclitaxel}
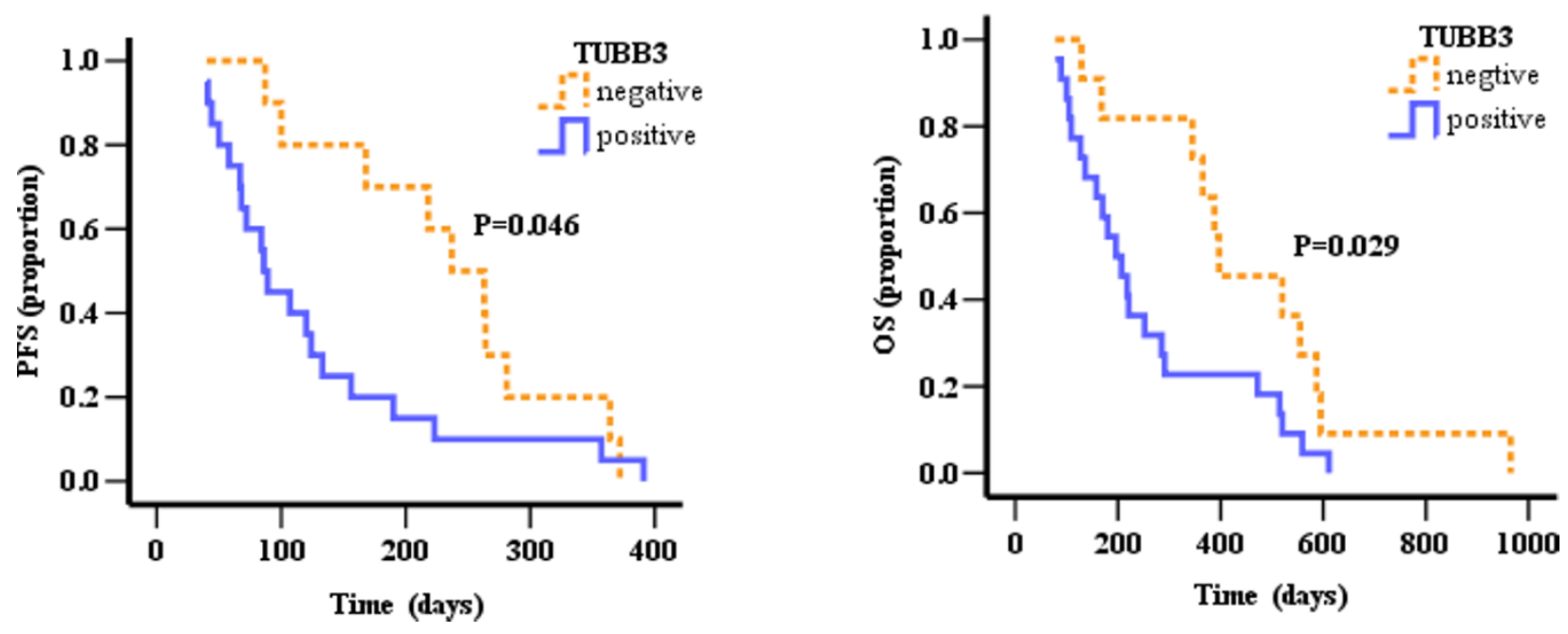

Figure 2 PFS and OS curves for TUBB3 negative and positive patients receiving capecitabine plus paclitaxel 


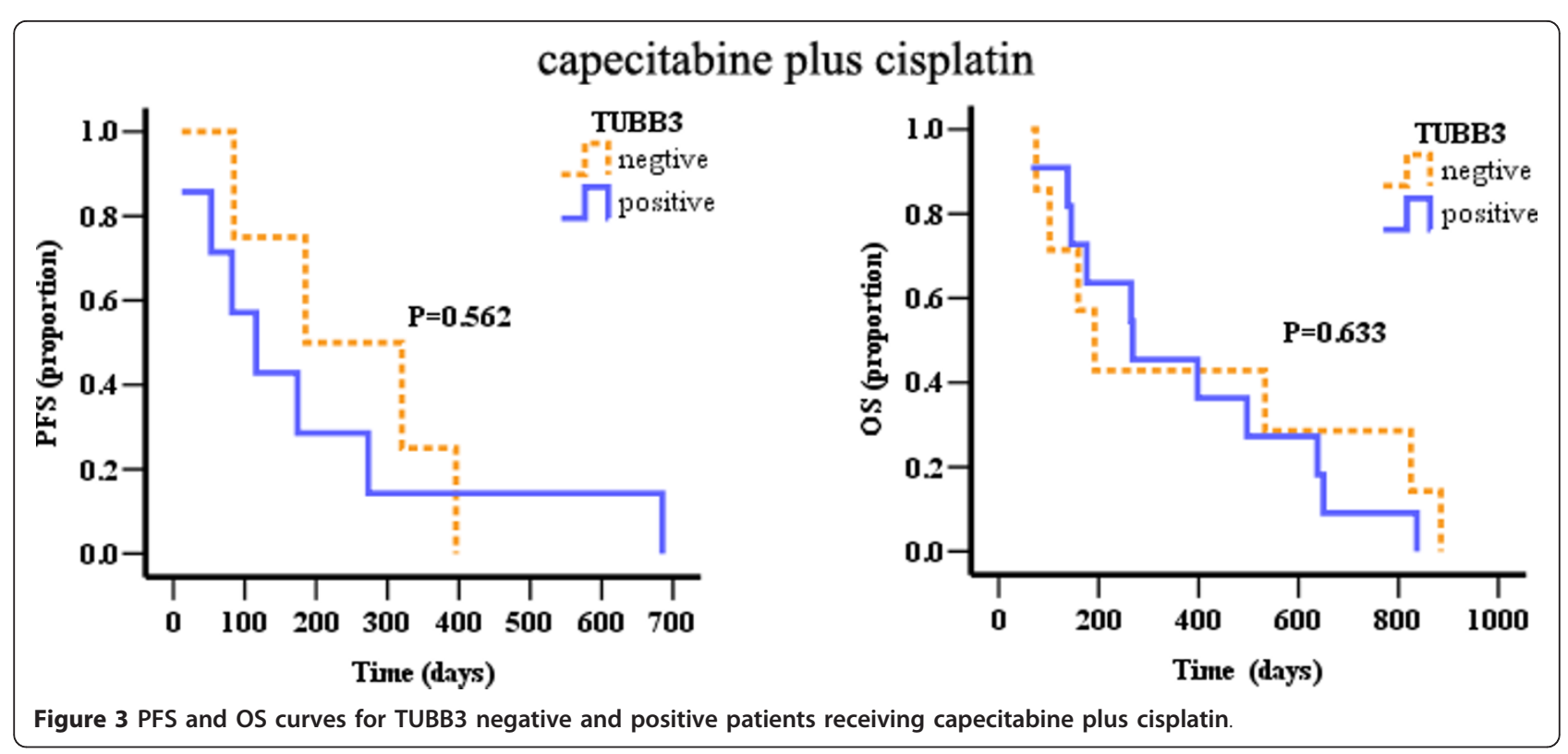

Taxanes are a kind of antitumor drugs and mechanisms about its resistance have been studied for a long time. Microtubule is the target of paclitaxel which induces microtubule stabilization, inhibits microtubule dynamics and interrupts cell divisions. Studies showed that TUBB3 high expressed in paclitaxel-resistant cells [37] and after transfecting TUBB3 cDNA into mammalian cells, cells with TUBB3 expression displayed resistant to paclitaxel [38]. Also in other studies about breast cancer, ovary cancer, head and neck neoplasms, there were relationship between TUBB3 expression and response or survival of paclitaxel. We studied the correlation in 33 samples treated with capecitabine plus paclitaxel, and found that the response rate for TUBB3 negative patients was $72.7 \%$, but only $36.4 \%$ in TUBB3 positive patients. Moreover, in cohort 1 , the prognosis of TUBB3 negative patients was much better than that of TUBB3 positive patients. Our results indicated there was not relationship between TUBB3 expression and response or survival in patients receiving capecitabine plus cisplatin, so TUBB3 expression could act as a predictor of paclitaxel efficacy.

TP could be upregulated after the treatment of taxane in preclinical trial [39], we analyzed the relationship between TP, TUBB3 expressions and the response or survival of patients. Interestingly, the response rate in TP positive \& TUBB3 negative patients was $87.5 \%$, but only $14.3 \%$ in TP negative \& TUBB3 positive patients. This result will need to be further confirmed in future studies.

Recently, many studies put the sights into genomic polymorphisms in genes involved in drug metabolic pathway and correlated with the target of agents. Few genes have been used to guide clinical medication, such as K-RAS [40], C-KIT [41], EGFR [42], Her-2 [43], and so on, but for most drugs there were no predictive markers. According to our results, TP and TUBB3 may be

Table 5 Association Between TP, TUBB3 Expressions and Response or Survival

\begin{tabular}{|c|c|c|}
\hline & \multicolumn{2}{|c|}{ TP, TUBB3 Staining } \\
\hline & TP positive \& TUBB3 negative & TP negative \& TUBB3 positive \\
\hline CR+PR No. & 7 & 1 \\
\hline SD No. & 1 & 3 \\
\hline PD No. & 0 & 3 \\
\hline Response rate (\%) & 87.5 & 14.3 \\
\hline$P$ & \multicolumn{2}{|c|}{0.01} \\
\hline $\begin{array}{l}\text { Median PFS (days) } \\
(95 \% \mathrm{CI})\end{array}$ & $\begin{array}{c}251 \\
(146.4-354.6)\end{array}$ & $\begin{array}{c}84 \\
(52.5-110.7)\end{array}$ \\
\hline$P$ & \multicolumn{2}{|c|}{0.003} \\
\hline $\begin{array}{l}\text { Median OS (days) } \\
(95 \% \mathrm{CI})\end{array}$ & $\begin{array}{c}393 \\
(340.9-530.8)\end{array}$ & $\begin{array}{c}196 \\
(70.3-461.7)\end{array}$ \\
\hline$P$ & \multicolumn{2}{|c|}{0.439} \\
\hline
\end{tabular}




\section{capecitabine plus paclitaxel}
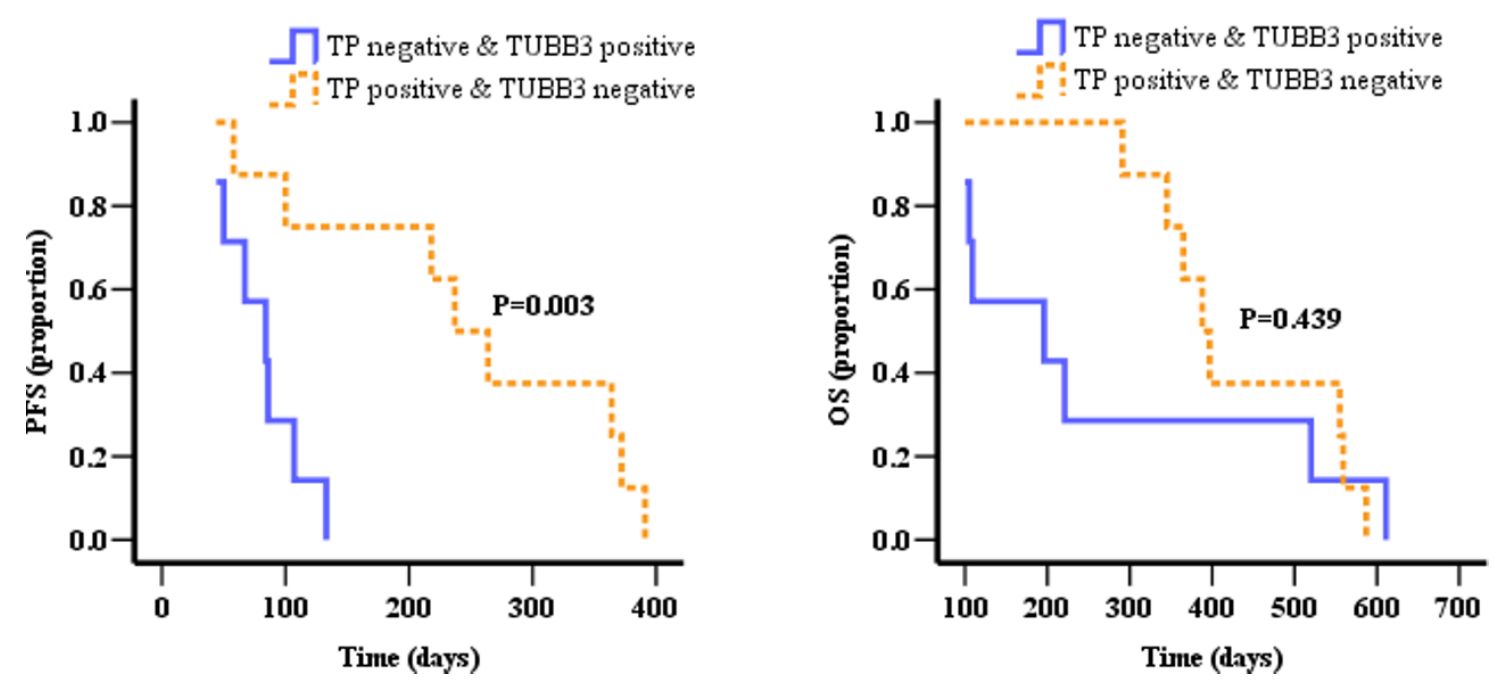

Figure 4 PFS and OS curves for TP negative \& TUBB3 positive and TP positive \& TUBB3 negative patients receiving capecitabine plus paclitaxel.

prospective to be used to predict the response and survival of capecitabine and paclitaxel.

To summarize our results, our findings demonstrate it's possible that overexpression of TUBB3 is the major reason of paclitaxel resistance in gastric cancer, and positive TP \& negative TUBB3 expressions might predict response and prognosis to capecitabine plus paclitaxel chemotherapy in AGC.

\section{Conclusions}

Our findings suggested that, in Chinese advanced gastric cancer, TP positive \& TUBB3 negative expressions might predict response and prognosis to capecitabine plus paclitaxel chemotherapy. Further prospective evaluation in large samples should be performed to confirm these preliminary results.

\section{Acknowledgements}

This work was supported by National High Technology Research and Development Program of China, Grant number: 2006AA02A402. The authors thank Dr. Bin Dong (Peking University School of Oncology, Beijing Cancer Hospital \& Institute) for IHC analysis and Dr. Ji-ping Yue (Infections and Cancer Biology Group, International Agency for Research on Cancer, Lyon, France) for critical reading of the manuscript.

\section{Authors' contributions}

Jing Gao and Ming Lu contributed equally to this work; Jing Gao, Ming Lu and Yan-yan Li performed the experiments; Jing Gao wrote the manuscript Jing-wei Yu performed the statistical analysis; Lin Shen designed the experiments and revised the manuscript. All authors have read and approved the final manuscript.

\section{Declaration of competing interests}

The authors declare that they have no competing interests.
Received: 22 December 2010 Accepted: 18 May 2011

Published: 18 May 2011

References

1. Ferlay J, Shin HR, Bray F, Forman D, Mathers C, Parkin DM: Estimates of worldwide burden of cancer in 2008: GLOBOCAN 2008. Int I Cancer 2010, 127:2893-2917.

2. Sun XD, Mu R, Zhou YS, Dai XD, Zhang SW, Huangfu XM, Sun J, Li LD, Lu FZ, Qiao YL: Analysis of mortality rate of stomach cancer and its trend in twenty years in China. Chin J Oncol 2004, 26:4-9.

3. Murad AM, Santiago FF, Petroianu A, Rocha PRS, Rodrigues MAG: Modified therapy with 5-fluorouracil, doxorubicin, and methotrexate in advanced gastric cancer. Cancer 1993, 72:37-41.

4. Pyrhonen $\mathrm{S}$, Kuitunen $\mathrm{T}$, Nyandoto $\mathrm{P}$, Kouri M: Randomised comparison of fluorouracil, epidoxorubicin and methotrexate (FEMTX) plus supportive care with supportive care alone in patients with non-resectable gastric cancer. Br J Cancer 1995, 71:587-591.

5. Glimelius B, Ekstrom K, Hoffman K, Graf W, Sjoden PO, Haglund U, Svensson C, Enander LK, Linne T, Sellstrom H, Heuman R: Randomized comparison between chemotherapy plus best supportive care with best supportive care in advanced gastric cancer. Ann Oncol 1997, 8:163-168.

6. Thuss-Patience PC, Kretzschmar A, Deist T, Hinke A, Bichev D, Lebedinzew B, Schumacher G, Gebauer B, Maier V, Reichardt P: Irinotecan versus best supportive care (BSC) as second-line therapy in gastric cancer: A randomized phase III study fo the Arbeitsgemeinschaft Internistische Onkologie (AIO). J Clin Oncol 2009, 27:15s, abstr 4540.

7. Ichikawa W: Prediction of clinical outcome of fluoropyrimidine-based chemotherapy for gastric cancer patients, in terms of the 5 -fluorouracil metabolic pathway. Gastric cancer 2006, 9:145-155.

8. Han JY, Hong EK, Lee SY, Yoon SM, Lee DH, Lee JS: Thymidine phosphorylase expression in tumour cells and tumour response to capecitabine plus docetaxel chemotherapy in non-small cell lung cancer. J Clin Pathol 2005, 58:650-654.

9. Uchida K, Danenberg PV, Danenberg KD, Grem JL: Thymidylate synthase, Dihydropyrimidine dehydrogenase, ERCC1, and thymidine phosphorylase gene expression in primary and metastatic gastrointestinal adenocarcinoma tissue in patients treated on a phase I trial of oxaliplatin and capecitabine. BMC Cancer 2008, 8:386-395.

10. Andreetta C, Puppin C, Minisini A, Valent F, Pegolo E, Damante G, Di Loreto C, Pizzolitto S, Pandolfi M, Fasola G, Piga A, Puglisi F: Thymidine 
phosphorylase expression and benefit from capecitabine in patients with advanced breast cancer. Annals of Oncology 2009, 20:265-271.

11. Saito K, Khan K, Yu SZ, Ronson S, Rhee J, Li G, Van Echo D, Suntharalingam M, O'Malley BW Jr, Li D: The Predictive and Therapeutic Value of Thymidine Phosphorylase and Dihydropyrimidine Dehydrogenase in Capecitabine (Xeloda)-Based Chemotherapy for Head and Neck Cancer. The Laryngoscope 2009, 119:82-88

12. Cunningham D, Starling N, Rao S, Iveson T, Nicolson M, Coxon F, Middleton G, Daniel F, Oates J, Norman AR, Upper Gastrointestinal Clinical Studies Group of the National Cancer Research Institute of the United Kingdom: Capecitabine and Oxaliplatin for Advanced Esophagogastric Cancer. N Engl J Med 2008, 358:36-46.

13. Kang YK, Kang WK, Shin DB, Chen J, Xiong J, Wang J, Lichinitser M, Guan Z, Khasanoy R, Zheng L, Philco-Salas M, Suarez T, Santamaria J, Forster G, McCloud PI: Capecitabine/cisplatin versus 5 -fluorouracil/cisplatin as firstline therapy in patients with advanced gastric cancer: a randomised phase III noninferiority trial. Ann Oncol 2009, 20:666-673.

14. Baize N, Abakar-Mahamat A, Mounier N, Berthier F, Caroli-Bosc FX: Phase II study of paclitaxel combined with capecitabine as second-line treatment for advanced gastric carcinoma after failure of cisplatin-based regimens. Cancer Chemother Pharmacol 2009, 64:549-55.

15. Kang HJ, Chang HM, Kim TW, Ryu MH, Sohn HJ, Yook JH, Oh ST, Kim BS, Lee JS, Kang YK: A phase II study of paclitaxel and capecitabine as a firstline combination chemotherapy for advanced gastric cancer. $\mathrm{Br} J$ Cancer 2008, 98:316-322.

16. Jordan MA: Mechanism of action of antitumor drugs that interact with microtubules and tubulin. Curr Med Chem Anticancer Agents 2002, 2:1-17.

17. Horwitz SB, Lothstein L, Manfredi JJ, Mellado W, Parness J, ROY SN, Schiff PB, Sorbara L, Zeheb R: Taxol: mechanisms of action and resistance. Ann N Y Acad Sci 1986, 466:733-44.

18. Giannakakou P, Sackett DL, Kang YK, Zhan Z, Buters JTM, Fojo T, Poruchynsky MS: Paclitaxel-resistant human ovarian cancer cells have mutant $\beta$-tubulins that exhibit impaired paclitaxel-driven polymerization. J Biol Chem 1997, 272:17118-25.

19. Monzó M, Rosell R, Sánchez JJ, Lee JS, O'Brate A, González-Larriba JL, Alberola V, Lorenzo JC, Núñez L, Ro JY, Martín C: Paclitaxel resistance in non-small-cell lung cancer associated with beta-tubulin gene mutations. J Clin Oncol 1999, 17:1786-93.

20. Mozzetti S, Ferlini C, Concolino P, Filippetti F, Raspaglio G, Prislei S, Gallo D, Martinelli E, Ranelletti FO, Ferrandina G, Scambia G: Class III $\beta$-Tubulin Overexpression Is a Prominent Mechanism of Paclitaxel Resistance in Ovarian Cancer Patients. Clinical Cancer Research 2005, 11:298-305.

21. Lu Q, Luduena RF: Removal of $\beta$ III isotype enhances taxol induced microtubule assembly. Cell Struct Funct 1993, 18:173-82.

22. Kavallaris M, Kuo DY, Burkhart CA, Regl DL, Norris MD, Haber M, Horwitz SB: Taxol-resistant epithelial ovarian tumors are associated with altered expression of specific $\beta$-tubulin isotypes. J Clin Invest 1997, 100:1282-93.

23. Sève $P$, Mackey J, Isaac $S$, Tredan $O$, Souquet PJ, Perol M, Lai R, Voloch $A$, Dumontet G: Class III $\beta$-tubulin expression in tumor cells predicts response and outcome in patients with non-small cell lung cancer receiving paclitaxel. Molecular Cancer Therapeutics 2005, 4:2001-2007.

24. Ranganathan S, Benetatos CA, Colarusso PJ, Dexter DW, Hudes GR: Altered beta-tubulin isotype expression in paclitaxel-resistant human prostate carcinoma cells. Br J Cancer 1998, 77:562-6.

25. Burkhart CA, Kavallaris M, Horwitz SB: The role of beta-tubulin isotypes in resistance to antimitotic drugs. Biochim Biophys Acta 2001, 1471:1-9.

26. Azuma K, Sasada T, Kawahara A, Takamori S, Hattori S, Ikeda J, Itoh K, Yamada A, Kage M, Kuwano M, Aizawa H: Expression of ERCC1 and class III beta-tubulin in non-small cell lung cancer patients treated with carboplatin and paclitaxel. Lung Cancer 2009, 64:326-33.

27. Ferrandina G, Zannoni GF, Martinelli E, Paglia A, Gallotta V, Mozzetti S, Scambia G, Ferlini C: Class III beta-tubulin overexpression is a marker of poor clinical outcome in advanced ovarian cancer patients. Clin Cancer Res 2006, 12:2774-9.

28. Paradiso A, Mangia A, Chiriatti A, Tommasi S, Zito A, Latorre A, Schittulli F, Lorusso V: Biomarkers predictive for clinical efficacy of taxol-based chemotherapy in advanced breast cancer. Annals of Oncology 2005, 16:14-19.

29. Urano N, Fujiwara Y, Hasegawa S, Miyoshi Y, Noguchi S, Takiguchi S, Yasuda T, Yano M, Monden M: Absence of beta-tubulin gene mutation in gastric carcinoma. Gastric Cancer 2003, 6:108-12.
30. Therasse P, Arbuck SG, Eisenhauer EA, Wanders J, Kaplan RS, Rubinstein L, Verweij J, Van Glabbeke M, van Oosterom AT, Christian MC, Gwyther SG: New guidelines to evaluate the response to treatment in solid tumors. European Organization for Research and Treatment of Cancer, National Cancer Institute of the United States, National Cancer Institute of Canada. J Natl Cancer Inst 2000, 92:205-216.

31. Kwon HC, Roh MS, Oh SY, Kim SH, Kim MC, Kim JS, Kim HJ: Prognostic value of expression of ERCC1, thymidylate synthase, and glutathione Stransferase P1 for 5-fluorouracil/oxaliplatin chemotherapy in advanced gastric cancer. Annals of Oncology 2007, 18:504-509.

32. Kolinsky K, Zhang YE, Dugan U, Heimbrook D, Packman K, Higgins B: Novel Regimens of Capecitabine Alone and Combined with Irinotecan and Bevacizumab in Colorectal Cancer Xenografts. Anticancer Research 2009, 29:91-98.

33. Sawada N, Kondoh K, Mori K: Enhancement of capecitabine efficacy by oxaliplatin in human colorectal and gastric cancer Xenografts. Oncology Report 2007, 18:775-778.

34. Ishitsuka H: Capecitabine: preclinical pharmacology studies. Invest New Drugs 2000, 18:343-354.

35. Meropol NJ, Gold PJ, Diasio RB, Andria M, Dhami M, Godfrey T, Kovatich AJ, Lund KA, Mitchell E, Schwarting R: Thymidine phosphorylase expression is associated with response to capecitabine plus irinotecan in patients with metastatic colorectal cancer. Journal of Clinical Oncology 2006, 24:4069-4077.

36. Koopman M, Venderbosch S, van Tinteren H, Ligtenberg MJ, Nagtegaal I, Van Krieken JH, Punt CJ: Predictive and prognostic markers for the outcome of chemotherapy in advanced colorectal cancer, a retrospective analysis of the phase III randomised CAIRO study. Eur J Cancer 2009, 45:1999-2006.

37. Mozzetti S, lantomasi R, Maria ID, Prislei S, Mariani M, Camperchioli A, Bartollino S, Gallo D, Scambia G, Ferlini C: Molecular mechanisms of patupilone resistance. Cancer research 2008, 8:10197-10204.

38. Takeda M, Mizokami A, Mamiya K, Li YQ, Zhang J, Keller ET, Namiki M: The Establishment of Two Paclitaxel-Resistant Prostate Cancer Cell Lines and the Mechanisms of Paclitaxel Resistance with Two Cell Lines. Prostate 2007, 67:955-967.

39. Maher JF, Villalona-Calero MA: Taxanes and capecitabine in combination: rationale and clinical results. Clin Breast Cancer 2002, 2:287-93.

40. Karapetis CS, Khambata-Ford S, Jonker DJ, O'Callaghan CJ, Tu D, Tebbutt NC, Simes RJ, Chalchal H, Shapiro JD, Robitaille S, Price TJ, Shepherd L, Au HJ, Langer C, Moore MJ, Zalcberg JR: K-ras Mutations and Benefit from Cetuximab in Advanced Colorectal Cancer. The New England Journal of Medicine 2008, 359:1757-1765.

41. Heinrich MC, Corless CL, Demetri GD, Blanke CD, von Mehren M, Joensuu H, McGreevey LS, Chen CJ, Van den Abbeele AD, Druker BJ, Kiese B, Eisenberg B, Roberts PJ, Singer S, Fletcher CD, Silberman S, Dimitrijevic S, Fletcher JA: Kinase Mutations and Imatinib Response in Patients With Metastatic Gastrointestinal Stromal Tumor. Journal of Clinical Oncology 2003, 21:4342-4349.

42. Bai H, Mao L, Wang SH, Zhao J, Yang L, An TT, Wang X, Duan JC, Wu MN, Guo QZ, Liu XY, Liu NH, Wang YY, Wang J: Epidermal Growth Factor Receptor Mutations in Plasma DNA Samples Predict Tumor Response in Chinese Patients With Stages IIIB to IV Non-Small-Cell Lung Cancer. Journal of Clinical Oncology 2009, 27:2653-2659.

43. Petit T, Borel C, Ghnassia JP, Rodier JF, Escande A, Mors R, Haeqeie P: Chemotherapy Response of Breast Cancer Depends on HER-2 Status and Anthracycline Dose Intensity in the Neoadjuvant Setting. Clinical Cancer Research 2001, 7:1577-1581

\section{Pre-publication history}

The pre-publication history for this paper can be accessed here: http://www.biomedcentral.com/1471-2407/11/177/prepub

\section{doi:10.1186/1471-2407-11-177}

Cite this article as: Gao et al:: Thymidine Phosphorylase/ $\beta$-tubulin III expressions predict the response in Chinese advanced gastric cancer patients receiving first-line capecitabine plus paclitaxel. BMC Cancer 2011 11:177. 